\title{
Use of Probiotic Yogurt in the Management of Acute Diarrhoea in Children. Randomized, Double-Blind, Controlled Study
}

\author{
Giuseppe Grandy ${ }^{1}$, Zdenka Jose ${ }^{1}$, Richard Soria ${ }^{1}$, Jennifer Castelú ${ }^{1}$, Anelisse Perez ${ }^{1}$, \\ Jose P. Ribera ${ }^{3}$, Oscar Brunser ${ }^{2}$ \\ ${ }^{1}$ Paediatric Centre Albina Patiño, Department of Gastroenterology and Nutrition, Cochabamba, Bolivia \\ ${ }^{2}$ Institute of Nutrition and Food Technology, University of Chile, Santiago, Chile \\ ${ }^{3}$ Albina Patiño Foundation, Cochabamba, Bolivia \\ Email: "ggrandy@inta.cl
}

Received 11 December 2013; revised 10 January 2014; accepted 18 January 2014

Copyright (C) 2014 by authors and Scientific Research Publishing Inc.

This work is licensed under the Creative Commons Attribution International License (CC BY).

http://creativecommons.org/licenses/by/4.0/

(c) (i) Open Access

\begin{abstract}
Background: In Bolivia there are few probiotic preparations available in the market, practically without alternatives to the use of freeze-dried products. An alternative used as a good alternative in other parts of the world is yogurt with a probiotic strain added. In this study we report the use of a locally prepared yogurt with a lyophilized probiotic added. Methods: This is randomized, double-blind and controlled clinical trial in children hospitalized with acute diarrhoea carried out at the Paediatric Centre Albina Patiño in Cochabamba, Bolivia with children 10 to 35 months participating. Children were randomly assigned to receive an oral rehydration solution and Saccharomyces boulardii (positive control) or the same solution plus yogurt preparation containing Lactobacillus rhamnosus (yogurt group). The primary outcome was the duration of diarrhoea. Secondary outcomes were the duration of fever, vomiting and hospitalization. Results: 0 of the $\mathbf{7 4}$ children incorporated 42 completed the protocol; baseline characteristics were similar in both groups. The median duration of diarrhoea was similar in children who received yogurt (71 hours) and controls ( 79 hours) $(\mathrm{p}=0.3)$. The mean duration of fever was also similar in both groups: $S$. boulardii (24 hours) or yogurt (11 hours) $(\mathrm{p}=1.02)$, as was the duration of vomiting: 17 hours vs. 32 hours in the control group $(p=0.37)$. A significant difference in the numbers of daily bowel movements was observed in the third day, the probiotic group was lower $(p=<0.01)$. There was no effect on the duration of hospitalization $(p=0.26)$. Conclusions: The use of a yogurt containing $L$. rhamnosus has an effect comparable to $S$. boulardii. Introduction of yoghurt with a probiotic in the diet of patients hospitalized with acute diarrhoea may help reduce its duration, regardless of its aetiology.
\end{abstract}

"Corresponding author.

How to cite this paper: Grandy, G., et al. (2014) Use of Probiotic Yogurt in the Management of Acute Diarrhoea in Children. Randomized, Double-Blind, Controlled Study. Open Journal of Pediatrics, 4, 54-61.

http://dx.doi.org/10.4236/ojped.2014.41007 


\section{Keywords}

\section{Probiotics; Yogurt; Diarrhoea and Children}

\section{Background}

Diarrhoea is the second most common infectious disease in children, and causes a significant number of hospitalizations, morbidity and mortality. In both developed and developing [1] countries, viruses are the leading cause of the episodes of acute diarrhoea, with rotavirus predominating. Worldwide rotavirus-associated diarrhoea is responsible for about 600,000 deaths annually and approximately $40 \%$ of the hospitalizations for diarrhoea in children under 5 years of age [2]. In Latin America rotavirus causes approximately 75,000 hospitalizations and about 15,000 deaths each year [3]. In Bolivia acute diarrhoea affects approximately $25 \%$ of the children under 5 years [4]. Cochabamba is a city of approximately 700.000 inhabitants in the central part of the Bolivian Andes and acute diarrhoea is one of the main causes of consultation and hospitalization in children. A study conducted some 10 years ago determined that the prevalence of diarrhoea was $19 \%$ in children fewer than 5 years of age that generated $24 \%$ of the outpatient consultations and accounted for $17 \%$ of hospitalizations [5].

In essence, the management of acute diarrhoea consists of the replacement of fluid losses, mainly by oral rehydration [6]; because of the high prevalence of diarrhoea one of the aims of its treatment is to shorten the time spent replacing this loss of fluids through diarrhoea and vomiting and shortening the duration of the illness, particularly in the case of hospitalized patients [7]. In this respect, in a study performed in our Centre probiotics were demonstrated to represent a useful alternative [8]. On the other hand, it has been shown that the Lactobacillus rhamnosus GG decreases the excretion of rotavirus during episodes of acute diarrhoea [9], and probably this decreases the risk of transmission of rotavirus to healthy individuals, a fact that may exert a significant epidemiological impact.

In the Bolivian market there are few preparations that contain probiotics, and for this reason there is practically no alternative to the freeze-dried probiotic-containing products. An alternative method used in other parts of the world is the addition of probiotics to food; in this respect yogurt with an added probiotic strain may represent a useful alternative [10]. In the current study we present the results of the use of a yogurt with lyophilized L. rhamnosus added in the management of acute diarrhoea.

\section{Methods}

The study is s randomized, double-blind, controlled trial, conducted at the Albina Patiño Paediatric Centre in Cochabamba, Bolivia, in children 10 to 36 months of age who were hospitalized with the diagnosis of acute diarrhoea. This was defined as the passage of 3 or more liquid stools and/or a change of consistency from normal to liquid but without visible blood or an increase above the normal daily frequency of evacuations in a 24-hour period. Patients were included in the study if their parents signed a written, informed consent after the purposes of the study had been explained to them.

The participating infants had to be well hydrated or have minimal $(<5 \%)$ or moderate $(5 \%-10 \%)$ dehydration as defined by the WHO [11]. Children with severe dehydration were not included $(>10 \%)$ in this protocol, as were those children who became dehydrated during their treatment. The exclusion criteria were moderate to severe malnutrition evaluated according to the WHO tables of growth for children fewer than 5 years, using z-score weight/height. Severe electrolyte disturbances (hypernatremia, hypokalaemia) or clinical or other laboratory signs of coexisting diseases such as sepsis, pneumonia, urinary tract infection or immune deficiencies were also excluded.

Infants with moderate dehydration received parenteral hydration, with glucose-electrolyte solution with added potassium (NA: $77 \mathrm{mEq} / \mathrm{L} ; \mathrm{K}: 30 \mathrm{mEq} / \mathrm{L}$; Cl: $107 \mathrm{mEq} / \mathrm{L}$; glucose: $137 \mathrm{mEq} / \mathrm{L}$.) at the time of admission for 2 at 3 hours, and once deemed appropriate on the basis of the improvement of their signs of dehydration and adequate urinary output they were switched to oral rehydration solution (Na $60 \mathrm{mEq}$; K $20 \mathrm{mEq}$; Cl $50 \mathrm{mEq}$; Citrate $30 \mathrm{mEq}$; glucose $111 \mathrm{mEq}$.) to a total volume of $10 \mathrm{~mL}$ per kilogram per hour. Additionally, all children received $20 \mathrm{mg}$ zinc sulphate daily throughout their hospital stay [12].

Children were randomly assigned to one of 2 groups by a Registered Nurse blindly pulling marked, numbered 
marbles; she was the only person who knew to which group belonged every subject: The study group (GY) received twice daily $50 \mathrm{ml}$ of a natural yogurt elaborated by Paurimani Bioagronomic Model Farm with $4.9 \times 10^{8}$ CFU/g of L. rhamnosus and $5 \times 10^{9} \mathrm{CFU} / \mathrm{g}$ of $L$. bulgaricus for 5 days. The personnel of the Nutrition Unit maintained the products frozen at $-4^{\circ} \mathrm{C}$ in 1 liter bottles and the $50 \mathrm{ml}$ aliquots were weighed in plastic disposable bottles and administered immediately to the children by the nurses. While receiving $50 \mathrm{ml}$ aliquots of a placebo product similar to probiotic lyophilized product. The control group (GC) received $5 \times 10^{9} \mathrm{CFU}$ lyophilized S. boulardii (Florestor; ${ }^{\circledR}$ Biocodex) dissolved in $50 \mathrm{ml}$ of water also twice daily according to the instructions provided by the manufacturer, and a yogurt without probiotic strain elaborated by Pairumani Brioagrnomic Model Farm with $5 \times 10^{9} \mathrm{CFU} / \mathrm{g}$ of $L$. bulgaricus (Table 1 ). If the child vomited, the administration of the respective repeated after 15 minutes. If the patient was discharged before the $5^{\text {th }}$ day, the parents continued the treatment at home.

Any problems with the consumption of the products were reported immediately to the principal investigator. Patients were re-evaluated at the Outpatient Department 24 to 48 hours after discharge.

The primary outcome of the study was the duration of the diarrhoea measured from the time of admission until the first normal evacuation was detected. Stool consistency was evaluated in a scale of 4 consistencies: liquid, semi-liquid, soft and formed. Secondary outcomes were the duration of vomiting, from admission until the last episode, the duration of fever considered as rectal temperature above $38^{\circ} \mathrm{C}$ also in hours, until discharge from the hospital.

For measurement of body length (height) a portable paidometer was used with a precision of $2 \mathrm{~mm}$ (model 207, Seca, Hamburg, Germany) and for body weight an electronic balance with a precision of 10 gram and 20 kilogram capacity (model 727, Seca, Hamburg, Germany) without diapers or clothing . Body length was measured on admission and at discharge while weight was measured daily.

On admission to the Hospital a complete medical history was obtained with focus on the history of the current episode, duration and severity prior to admission, previous drug use, and a physical examination was performed considering an evaluation of the nutritional state, signs of dehydration, fever, and oral tolerance to fluids and liquids. The presence of concomitant diseases (malnutrition, skin, urinary tract or respiratory infections) was evaluated.

Within three hours of admission at the most the following laboratory tests were performed on all participants: blood count (including measurement of haemoglobin, peripheral white cell count and differential formula), a semiquantitative C-reactive protein (Humatex CRP, Human Gesellschaft, Wiesbaden; Germany. Electrolyte concentrations in plasma: sodium, potassium, calcium, measured by flame photometry (Sherwood Range Model 140 Classic Flame Photometer, Sherwood Scientific Limited, Cambridge, UK). For the detection of rotavirus in faeces the Rida Quick Rotavirus kit was used (R-Biopharm, Darmstadt, Germany). Parasitological assessment by PAF technique by Lugol method [13]. Stool cultures were performed for enteropathogenic, toxigenic, enteroadhaerent, enteroaggregative, invasive and enterohaemorrhagic E. coli and for Salmonella typhi and Shigella spp using routine procedures (Agar Base, McConkey, SS Agar and Tetrathionate Broth Base (Bacto Difco, Kansas, USA). Other tests include urinary chemistries and sediment microscopic observation [14].

The study design and the written consent forms were approved by the Ethics and the Research Committees of the Albina Patiño Paediatric Centre. The medical staff and paramedical personnel were informed that would come into contact with the patients were informed in detail about the procedures they would be involved in during the study.

\subsection{Estimation of Sample Size}

The sample size calculation was made on the basis of a prior study carried out in our Centre [8] and it was esti-

Table 1. Microorganism's components in Studio products and main features of both preparations.

\begin{tabular}{cccc}
\hline Group & Microorganism & Dose (twice per day) & Commercial name \\
GY & L. Rhamnosus, & $\begin{array}{c}4.9 \times 10^{9} \text { lyophilized cells/dose } \\
\text { Equivalent to } 50 \mathrm{~mL} \text {. yogurt. }\end{array}$ & Probiotic yogurt \\
GC & S. Boulardii & $5 \times 10^{9}$ lyophilized live cells $/$ dose & Florestor \\
\hline
\end{tabular}

\footnotetext{
${ }^{*}$ The price of yogurt corresponds to the price of similar yoghurt with an increase of $30 \%$.
} 
mated that with a power of 0.8 and a significance of 0.05 , we required a total of 21 participants in each group; we also assumed that the study group would experience a shortening of 27 hours in the duration of the episode of diarrhoea when compared with the control group.

\subsection{Statistical Analysis}

Analyses were conducted between the control group and the study (L. rhamnosus) group. For statistical analysis for non-parametric statistic the Kruskall-Wallis as well as Mann-Whitney-U tests were used in comparing the median of continuous variables. The chi square test was used for categorical variables. Data were analysed using the statistical program STATA 9.2.

\section{Results}

As seen in the flowchart (Figure 1), out of a total of 224 breastfed hospitalised infants a total of 74 patients were included in the study; in the course of the study 32 patients dropped out because their parents requested their discharge or because of urinary tract infections due to Escherichia coli in all cases. This left 42 patients for the per protocol analysis. Seven of the remaining patients developed alterations of their plasma electrolyte levels despite adequate management of their dehydration because of increased vomiting and required more prolonged hospitalisation. Comparisons of the characteristics of the dropouts showed no differences between both groups.

These patients were grouped into 2 groups with similar basal characteristics (Table 2). The aetiology of the diarrheal episode was similar in both groups (Table 3). The duration of the diarrhoeal episodes was comparable in both groups, with $71 \pm 24$ (interquartile range, IQR) hours in the group that received the yogurt and $79 \pm$ 58 hours $(p=0.76)$ in the group that served as control (Table 4). Both groups had a similar number of patients with vomiting. The duration of fever was shorter in the yogurt group: 11 hours \pm 25 hours (IQR) compared to the control: $24 \pm 63$ hours, $p=0.3$. Vomiting was controlled earlier in the yogurt group, $17 \pm 44$ hrs compared to the control $32 \pm 47$ hours, but this difference was not significant $p=0.7$ (Table 5).

The evaluation of secondary outcomes showed that there were no statistically significant differences between the groups in the duration of hospitalization (Table 5). On the other hand, a significant difference in the numbers of daily bowel movements was observed in the third day, the probiotic group was lower (Figure 2).

\section{Discussion}

Despite improvements in the treatment and prevention of acute diarrhoea this condition still causes a large pro-

Table 2. Characteristics of infants admitted to the study.

\begin{tabular}{|c|c|c|c|}
\hline & $\begin{array}{c}\text { Control Group } \\
n=21\end{array}$ & $\begin{array}{c}\text { Group GY } \\
n=21\end{array}$ & P-value \\
\hline Number of male children (\%) & $12(57)$ & $11(52)$ & $\mathrm{NS}^{*}$ \\
\hline Median age, months (IQR) & $14(8)$ & $14(11)$ & $\mathrm{NS}^{\dagger}$ \\
\hline Medium weight, Gr. (IQR) & $8500(1700)$ & $8850(1690)$ & $\mathrm{NS}^{\dagger}$ \\
\hline Median days of diarrhoea prior to hospitalization (IQR) & $3(2)$ & $3(1)$ & $\mathrm{NS}^{\dagger}$ \\
\hline
\end{tabular}

IQR = Interquartile Range; ${ }^{*}$ Test Chi square; ${ }^{\dagger}$ Test U - Mann Whitney.

Table 3. Aetiology of diarrhoea in each study group episode.

\begin{tabular}{|c|c|c|c|}
\hline & $\begin{array}{c}\text { Control Group } \\
n=21(\%)\end{array}$ & $\begin{array}{c}\text { Group Yogurt } \\
n=21(\%)\end{array}$ & P-value* \\
\hline Rotavirus & $8(38)$ & 8 (38) & NS \\
\hline Giardia & $5(24)$ & $8(38)$ & NS \\
\hline Amoebae & $3(14)$ & $5(24)$ & NS \\
\hline Shigella & $2(10)$ & 0 & NS \\
\hline
\end{tabular}

\footnotetext{
${ }^{*}$ Test Chi square.
} 
Table 4. Main variable: duration of diarrhoea during admission to study groups.

\begin{tabular}{cccc}
\hline Group & Treatment & Median (IQR) duration (hrs.) & P-value \\
\hline 1 & L. Rhamnosus. & $71(24)$ & $\mathrm{NS}^{\dagger}$ \\
2 & S. Boulardii & $79(58)$ & \\
\hline
\end{tabular}

IQR = Interquartile Range; ${ }^{\dagger}$ Test or Mann - Whitney, p-value in comparison with the control group.

Table 5. Secondary variables, duration of fever and vomiting during hospitalization.

\begin{tabular}{|c|c|c|c|}
\hline & $\begin{array}{c}\text { Control Group } \\
n=21\end{array}$ & $\begin{array}{c}\text { Group Yogurt } \\
n=21\end{array}$ & $\mathrm{p}$ value \\
\hline Median hours of hospitalization (IQR) & 75 (39) & $86(49)$ & $\mathrm{NS}^{\mathrm{f}}$ \\
\hline $\mathrm{N}^{\circ}$ children with fever (\%) & $16(76)$ & $13(62)$ & NS * \\
\hline Median duration of fever in hrs. (IQR) & $24(63)$ & $11(25)$ & $\mathrm{NS}^{\epsilon}$ \\
\hline $\mathrm{N}^{\circ}$ children with vomiting (\%) & $12(57)$ & $10(48)$ & $\mathrm{NS}^{*}$ \\
\hline Median duration of vomiting in hrs. (IQR) & $32(47)$ & $17(44)$ & $\mathrm{NS}^{£}$ \\
\hline
\end{tabular}

IQR = Interquartile Range; ${ }^{*}$ Test Chi square; ${ }^{\text {E}}$ Test U - Mann Whitney.

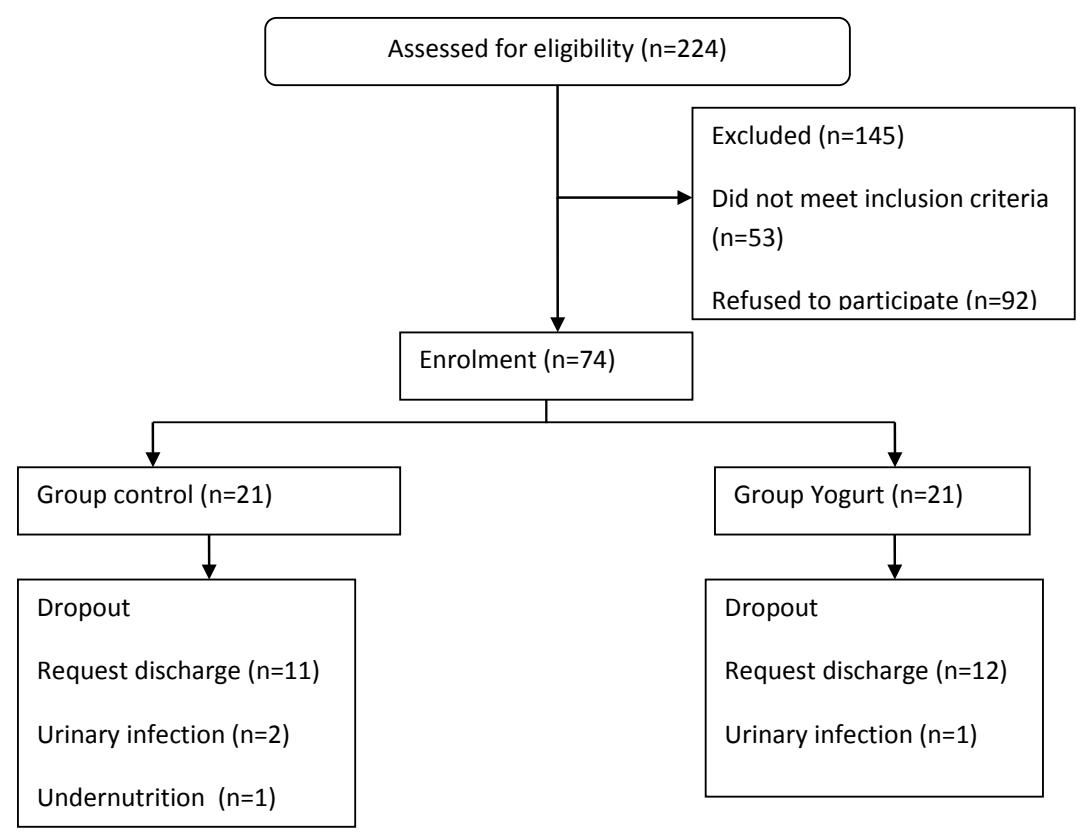

Figure 1. Participants through study flow diagram.

portion of the mortality and morbidity in infants, especially in the less developed countries. Furthermore, it is an important factor in the genesis of stunting and severe malnutrition. Diarrhoeal disease, if it evolves into more prolonged and chronic forms, may cause disturbances of the absorptive processes that become difficult to manage and require careful refeeding to promote the repair of the intestinal mucosa and the restitution of normal function. It is now agreed that earlier oral rehydration and adequate nutrition are the keystones of treatment and that only a small proportion of children may require antibiotics for treatment of specific microorganisms.

Probiotics have been defined as live microorganisms that, when ingested in adequate numbers, confer a health benefit on the host [15]. There is abundant literature that shows that probiotics are species- and strain-specific in their effects and most of the literature has been focused on the effects of those that have the GRAS denomination. Two of these probiotic microorganisms, Lactobacillus rhamnosus GG and Saccharomyces boulardii have been amply investigated for the prevention and treatment of infantile diarrhoea. 


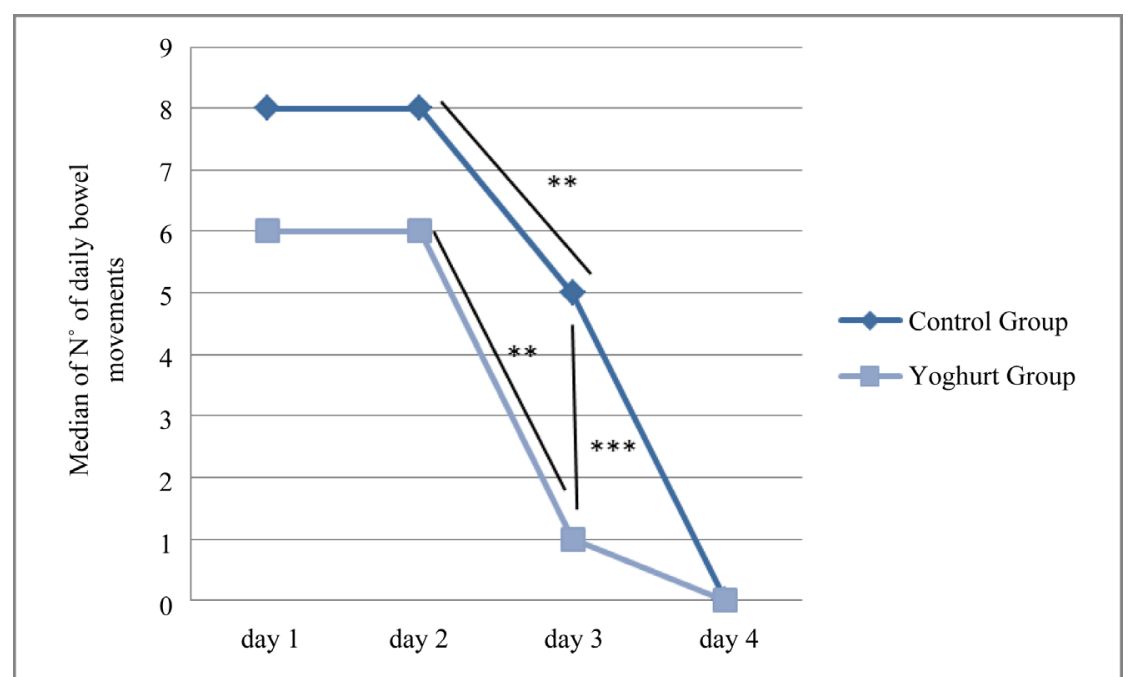

Figure 2. Number of bowel movements in each study group. Test Kruskall-Wallis. Significance in the same group $(\mathrm{p}=<0.01) .{ }^{* * *}$ Significance between groups $(\mathrm{p}=<$ $0.01)$.

In the present study no differences were found in the efficiency of both probiotics, a finding that leads us to suppose that their effects are roughly comparable and that the mechanisms through which the act may be similar. There are few studies about the use of yoghurt in acute diarrhoea. A study by Eren et al showed that in children 5 months to 16 years of age yoghurt fluid administration was associated with non-significantly shorter hospital stays compared to the children administered $S$. boulardii but that administration of this latter resulted in earlier resolution of the diarrhoea [16]. Another study with Kefir, product very similar to yogurt, with Lactococcus lactis, Lactococcus plantarum, Lactococcus rhamnosus, Lactococcus casei, Lactococcus lactis subspecies diacetylactis, Leuconostoc cremoris, Bifidobacterium longum, Bifidobacterium breve, Lactobacillus acidophilus, and Saccharomyces florentinus. In the prevention of antibiotics associated diarrhoea, there were no significant differences with placebo; rates of diarrhoea were similar in both groups [17]. Other studies support this finding that S. boulardii shortens the duration of diarrhoeas [18]-[21]; this decrease varies between 30 to 36 hours in comparison with the control group [19]-[22]. In our study the effect is probably comparable because the study of Eren and cols. uses a yogurt containing a smaller number of CFU $\left(10^{7} \mathrm{CFU} / 100 \mathrm{~mL}\right.$, unlike ours which provides $4.9 \times 10^{9} \mathrm{CFU} / 50 \mathrm{ml}$. some authors recently suggested a dose of at least $10 \times 10^{9} \mathrm{CFU}$ as minimum [22] [23] as required to have an adequate effect. However, this is not too different from the dosage we administered to our children.

The probiotic used in yogurt (L. rhamnosus), it is one of the most studied and there is evidence of positive effects in the management of acute diarrhoea. An interesting study shows a decrease in the shedding of rotavirus in the stool of affected patients [24] [25].

\section{Conclusions}

The probiotic yogurt has a positive effect in the management of acute diarrhoea in children, comparable to that of a well-described probiotic, Saccharomyces boulardii. In addition, it represents an economic alternative for management of children with diarrhoea in Bolivia.

It is important to mention the cost of our product, which is less than that of lyophilized products; this has repercussions on the household economy, especially in a country like ours where the purchasing power is low for a large proportion of the population.

\section{Competing Interests}

Jose Pedro Ribera is a member of the Ethics Committee of Paediatrics Centre Albina Patiño, but not participate in the review and approbation of the protocol of this study.

The other authors declare that they have no competing interests. 


\section{Acknowledgements}

This work was funded by the Albina Patiño Foundation; an independent, non-profit foundation created by Simon I. Patiño.

\section{References}

[1] Parashar, U.D., Holman R.C., Clarke, M.J., et al. (1998) Hospitalizations Associated with Rotavirus Diarrhoea in the United States, 1993 through 1995: Surveillance Based on the New ICD-9-CM Rotavirus-Specific Diagnostic Code. The Journal of Infectious Diseases, 177, 13-17. http://dx.doi.org/10.1086/513808

[2] Organization Pan-American Health (2007) Epidemiological Surveillance of Diarrhoea Caused by Rotavirus: Practical guide. Scientific Publication and Technical No. 623, PAHO, Washington DC.

[3] Castello, A.A., Arvay, M.L., Glass, R.I. and Gentsh, J. (2004) Rotavirus Strain Surveillance in Latin America: A Review of the Last Nine Years. The Pediatric Infectious Disease Journal, 23, S168-S172. http://dx.doi.org/10.1097/01.inf.0000142466.57262.2a

[4] Bolivia: Población menor de 5 años que se enfermó con diarrea aguda, según área y características de atención, 20002008. http://www.ine.gob.bo/indice/visualizador.aspx?ah=PC30119.HTM

[5] Romero, C., Mamani, N., Halvorsen, K., Íñiguez, V., et al. (2007) Diseases Diarrhoeal Acute Associated to Rotavirus. The Revista Chilena de Pediatría, 78, 549-558.

[6] Berni, C.R., Cirillo, P., Terrin, G., Cesarano, L., Spagnuolo, M.I., De Vincenzo, A., Albano, F., Passariello, A., De Marco, F., Manguso, F. and Guarino, A. (2007) Probiotics for Treatment of Acute Diarrhoea in Children; Randomized Clinical Trial of 5 Different Preparations. BMJ, 10, 335-340.

[7] Cucchiara, S., Falconieri, P., Di Nardo, G., et al. (2002) New Therapeutic Approach in the Management of Intestinal Disease: Probiotics in Intestinal Disease in Paediatric age. Digestive and Liver Disease, 34, S44-S47. http://dx.doi.org/10.1016/S1590-8658(02)80163-3

[8] Grandy, G., Medina, M., Soria, R., Terán, C.G. and Araya, M. (2010) Probiotics in the Treatment of Acute Diarrhoea in Children. BMC Infectious Diseases, 10, 253. http://dx.doi.org/10.1186/1471-2334-10-253

[9] Boirivant, M. and Strober, W. (2007) The Mechanism of Action of Probiotic. Current Opinion in Gastroenterology, 23, 679-692. http://dx.doi.org/10.1097/MOG.0b013e3282f0cffc

[10] Heydarian, F., Kianifar, H.R., Ahanchian. H., Khakshure, A., Seyedi, J. and Moshirian, D. (2010) A Comparison between Traditional Yogurt and Probiotic Yogurt in Non-Inflammatory Acute Gastroenteritis. Saudi Medical Journal, 31, 280-283.

[11] Kim, M.S. and Somers, M.J.G. (2006) Fluid and Electrolyte Physiology and Therapy. In: Oski, F.A., Ed., Oski’s Pediatrics: Principles and Practice. 4th Edition. Lippincott Williams \& Wilkins, Philadelphia, 54-70.

[12] Tratamiento Clínico de la Diarrea Aguda. http://whqlibdoc.who.int/hq/2004/WHO_FCH_CAH_04.7_spa.pdf

[13] Thompson, R.G. (1972) A Simple Concentration Method for the Detection of Parasitic Ova and Cysts in Faeces. J Clin Pathol, 25, 546-547. http://dx.doi.org/10.1136/jcp.25.6.546

[14] Urinalysis and Collection, Transportation, and Preservation of Urine Specimens, NCCLS GP-16A2, Vol. 21, No. 19, Approved Guideline, 2nd Edition, 4-21.

[15] Joint FAO/WHO Expert Consultation on Evaluation of Health and Nutritional: Properties of Probiotics in Food including Powder Milk with Live Lactic Acid Bacteria. ftp://ftp.fao.org/docrep/fao/009/a0512e/a0512e00.pdf

[16] Eren, M., Dinleyici, E.C. and Vandenplas, Y. (2010) Clinical Efficacy Comparison of Saccharomyces boulardii and Yogurt Fluid in Acute Non-Bloody Diarrhea in Children: A Randomized, Controlled, Open Label Study. The American Journal of Tropical Medicine and Hygiene, 82, 488-491. http://dx.doi.org/10.4269/ajtmh.2010.09-0529

[17] Daniel, J., Merenstein, M.D., Foster, J. and D’Amico, F. (2009) A Randomized Clinical Trial Measuring the Influence of Kefir on Antibiotic-Associated Diarrhea The Measuring the Influence of Kefir Study. Archives of Pediatrics and Adolescent Medicine, 163,750-754.

[18] Pham, M., Lemberg, D.A. and Day, A.S. (2008) Probiotics: Sorting the Evidence from the Myths. Medical Journal of Australia, 188, 304-308.

[19] Htwe, K., Yee, K.S., Tin, M. and Vandenplas. Y. (2008) Effect of Saccharomyces boulardii in the Treatment of Acute Watery Diarrhea in Myanmar Children: A Randomized Controlled Study. The American Journal of Tropical Medicine and Hygiene, 78, 214-216.

[20] Billoo, A.G., Memon, M.A., Khaskheli, S.A., Murtaza, G., Iqbal, K., Saeed Shekhani, M. and Siddiqi, A.Q. (2006) Role of a Probiotic (Saccharomyces boulardii) in Management and Prevention of Diarrhoea. World Journal of Gastroenterology, 12, 4557-4560. 
[21] Kurugöl, Z. and Koturoğlu, G. (2005) Effects of Saccharomyces boulardii in Children with Acute Diarrhoea. Acta Paediatrica, 94, 44-47. http://dx.doi.org/10.1080/08035250410022521

[22] Szajewska, H. and Mrukowicz, J.Z., (2001) Probiotics in the Treatment and Prevention of Acute Infectious Diarrhea in Infants and Children; A Systematic Review of Published Randomized, Double-Blind, Placebo-Controlled Trials. Journal of Pediatric Gastroenterology and Nutrition, 33, S17-S25. http://dx.doi.org/10.1097/00005176-200110002-00004

[23] Guandalini, S. (2008) Probiotics for Children with Diarrhoea: An Update. Journal of Clinical Gastroenterology, 42, S53-S57. http://dx.doi.org/10.1097/MCG.0b013e3181674087

[24] Szajewska, H., Setty, M., Mrukowicz, J. and Guandalini, S. (2006) Probiotics in Gastrointestinal Diseases in Children: Hard and Not-So-Hard Evidence of Efficacy. Journal of Pediatric Gastroenterology and Nutrition, 42, 454-475. http://dx.doi.org/10.1097/01.mpg.0000221913.88511.72

[25] Fang, S.B., Lee, H.C., Hu, J.J., Hou, S.Y., Liu, H.L. and Fang, H.W. (2009) Dose-Depend Effect of Lactobacillus rhamnosus on Quantitaive Reduction of Faecal Rotavirus Shedding in Children. Journal of Tropical Pediatrics, 55, 297-301. http://dx.doi.org/10.1093/tropej/fmp001 